Article

\title{
Population-Based Study of the Influence of the COVID-19 Pandemic on Hand Hygiene Behaviors-Polish Adolescents' COVID-19 Experience (PLACE-19) Study
}

\author{
Dominika Głąbska ${ }^{1, *(1)}$, Dominika Skolmowska ${ }^{1}\left(\mathbb{D}\right.$ and Dominika Guzek ${ }^{2} \mathbb{}$ \\ 1 Department of Dietetics, Institute of Human Nutrition Sciences, \\ Warsaw University of Life Sciences (SGGW-WULS), 159C Nowoursynowska Street, 02-776 Warsaw, Poland; \\ dominika_skolmowska@sggw.edu.pl \\ 2 Department of Food Market and Consumer Research, Institute of Human Nutrition Sciences, \\ Warsaw University of Life Sciences (SGGW-WULS), 159C Nowoursynowska Street, 02-776 Warsaw, Poland; \\ dominika_guzek@sggw.edu.pl \\ * Correspondence: dominika_glabska@sggw.edu.pl; Tel.: +48-22-593-71-26
}

Received: 18 May 2020; Accepted: 16 June 2020; Published: 17 June 2020

check for updates

\begin{abstract}
Due to the COVID-19 pandemic, the World Health Organization and other major authorities recommend frequent hand washing and applying proper hand hygiene procedures as one of the cheapest, easiest, and most important ways to prevent the spread of a virus. For adolescents it is especially important as it should become for them a lifelong habit. The aim of the study was to assess the hand hygiene behaviors during the COVID-19 pandemic in a national Polish sample of secondary school adolescents and to verify the influence of the COVID-19 pandemic on those behaviors. The study was conducted in April 2020 in a national sample of 2323 secondary school students recruited based on secondary school sampling procedure (random quota sampling with quotas for voivodeships). The hand hygiene behaviors that were assessed included: frequency of washing hands, reasons for not washing hands, circumstances of washing hands, and procedure of handwashing. Participants were asked each question twice-for the current period of the COVID-19 pandemic and for the period before the COVID-19 issue. The declared frequency of washing hands during the COVID-19 pandemic was significantly higher than before $(p<0.0001)$, as the majority of respondents declared doing it 6-15 times a day (58.4\%) while before the pandemic, it was 3-10 times a day $(68.1 \%)$. The share of respondents declaring washing their hands always while it would be needed was significantly higher for the period during the COVID-19 pandemic (54.8\%) than it was for the period before $(35.6 \% ; p<0.0001)$, and there was a lower share of respondents declaring various reasons for not washing hands. For the majority of circumstances of washing hands, including those associated with meals, personal hygiene, leaving home, socializing, health, and household chores, the share of respondents declaring always washing their hands was significantly higher for the period during the COVID-19 pandemic than for the period before $(p<0.0001)$. For the majority of steps of handwashing procedure, the share of respondents declaring including them always was significantly higher for the period during the COVID-19 pandemic than for the period before $(p<0.0001)$, but a higher share declared not wearing a watch and bracelet $(p=0.0006)$, and rings $(p=0.0129)$. It was concluded that during the COVID-19 pandemic all the assessed hand hygiene behaviors of Polish adolescents were improved, compared with those before, but hand hygiene education is still necessary.
\end{abstract}

Keywords: COVID-19; Coronavirus-19; SARS-CoV-2; hand hygiene; hand washing; adolescents; national population-based study; Polish Adolescents' COVID-19 Experience (PLACE-19) Cohort 


\section{Introduction}

The Coronavirus-19 disease (COVID-19), caused by severe acute respiratory syndrome coronavirus 2 (SARS-CoV-2), is responsible for the global pandemic that was declared by the World Health Organization (WHO) on March 11, 2020 [1]. In Poland, the first case was confirmed on 4 March 2020 and over 24 days after, the total number of confirmed infections was 1389, based on 34,000 laboratory tests performed [2]. Due to the fact that vaccines are currently being developed [3], other actions that may reduce the transmission are becoming necessary [4] and they are recommended by major authorities. Among such actions is proper hand hygiene. It was indicated by the WHO as the first action that should be taken by individuals to protect themselves and others, by washing hands frequently with water and soap or using hand-sanitizing gel [1]. Similarly, the United Nations International Children's Emergency Fund (UNICEF) released a statement that, during a global pandemic, one of the cheapest, easiest, and most important ways to prevent the spread of a virus is to wash hands frequently with soap and water [5]. Likewise, national organizations, such as the Centers for Disease Control and Prevention (CDC) of United States of America, emphasized that during the COVID-19 pandemic keeping hands clean is especially important to help prevent the virus from spreading [6]. The Polish Chief Sanitary Inspectorate also stated that the most important action that should be taken by all individuals is frequent hand washing [7], which was confirmed by the Polish National Institute of Public Health (NIH) [8].

There are some potential adverse dermatological events that may occur as a consequence of frequent hand washing, but it is indicated that in the current global context, they should in no way cause people to deviate from strict hand hygiene rules [9], and that the proper procedure may reduce the risk [10]. Moreover, in spite of the fact that some authors indicate that hand hygiene guidelines may generate a false illusion that they can prevent from acquiring or transmitting SARS-CoV-2 [11], it is still a major public health recommendation.

However, it is not only important to wash hands frequently, but also to do it properly, applying a proper procedure at the correct time [12]. There are specific recommendations by WHO [13] and UNICEF [5], indicating how, how long, and when hands should be washed, not only to reduce SARS-CoV-2 spreading, but also to reduce the risk of other infections. Moreover, it may be an action which allows the decrease of stress levels [14], which is an important consideration in the time of a pandemic or any other crisis [15].

The recently published study by Chen et al. [16], conducted in the Chinese population of school students in Wuhan in February 2020, indicated that almost $60 \%$ of respondents have improper hand-washing behaviors, so it may be stated to be a serious public health problem. Moreover, there are important individual determinants of hand washing hygiene behaviors, as was observed in Asian adolescents [17]. The group of adolescents is especially important, as dedicated education may significantly improve their hand hygiene behaviors [18]. It results from the fact that age [19] and education level [20] are significantly associated with hand hygiene behaviors, while independently from the country there are similar motivations towards them [21]. Moreover, hand hygiene behaviors may become lifelong habits [22], so the process of forming them should be conducted before adulthood [23].

Taking into account the current global situation associated with the major public health issue, the aim of the present study was to assess the hand hygiene behaviors during the COVID-19 pandemic in a national Polish sample of secondary school adolescents and to verify the influence of the COVID-19 pandemic on those behaviors.

\section{Materials and Methods}

\subsection{Studied Group}

The studied group was recruited within the Polish Adolescents' COVID-19 Experience (PLACE-19) Study. The study was conducted in cooperation with local Boards of Education in a population of secondary school students in all the regions of Poland. In Poland, current Net Enrollment Rate (NER) 
for this education level is estimated as $89.38 \%$ (based on the data of the Central Statistical Office in Poland for December 2019 [24]), and the typical age of students for this education level is 15-20 years.

The respondents were recruited in a two-stage stratified sampling procedure, while a random quota sampling was applied with quotas for voivodeships of Poland:

- First stage (2 weeks, from March 31, 2020 to April 14, 2020): conducted for all 16 voivodeships (within 6 regions of Poland). For each voivodeship, 5 counties were randomly selected, and for each county, 5 secondary schools, resulting in random selection of 25 secondary schools for each voivodeship (400 secondary schools randomly selected for Poland);

- Second stage (2 weeks, from April 15, 2020 to April 29, 2020): conducted for 10 voivodeships (within 6 regions of Poland), for which during the first stage, a number of 50 respondents was not gathered. For each voivodeship, 5 counties were randomly selected, and for each county, 5 secondary schools, resulting in random selection of 25 secondary schools for each voivodeship (250 secondary schools randomly selected for Poland).

The principal of each randomly selected school was informed about the study and he received a link to the online version of the questionnaire generated for the students of his school. If needed, the local Boards of Education participated in formal arrangements. During each phase, at the halfway point, each principal whose students had not completed the questionnaire, received a reminder.

The inclusion criteria for the study were age of $15-20$ years and being a student of the randomly selected school. Both were verified based on the answers in the questionnaire. The exclusion criteria were any missing data in the questionnaire and unreliable answers in the questionnaire.

After the recruitment procedure and two stages of the study, the data were gathered for a population of 2323 secondary school students from Poland who met the inclusion criteria and provided reliable answers. The distribution of included schools within regions of Poland was in agreement with the distributions of all registered secondary schools in Poland. The procedures of sampling, recruitment, and inclusion are presented in Figure 1.

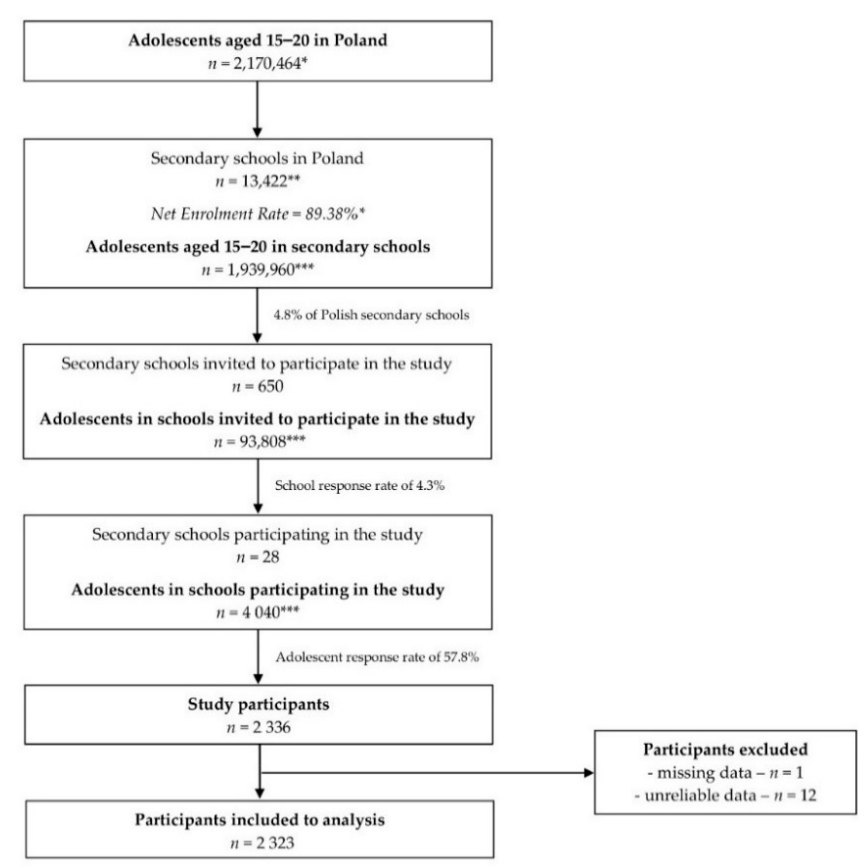

Figure 1. The procedures of sampling, recruitment, and inclusion for the studied group of the Polish adolescents. * data of the Central Statistical Office (CSO) [24,25]; ** data of the Polish Ministry of National Education [26]; ${ }^{* * *}$ calculated based on CSO data. 


\subsection{Applied Questionnaire}

The study was conducted in the period after declaring a COVID-19 global pandemic by WHO (March 11, 2020) [1] and after a decision of Polish Ministry of National Education to temporarily suspend all lectures and classes in all schools in Poland, including secondary schools (12 March 2020) [27]. During the study, all the secondary school students were in the system of remote learning and they were recommended to stay at home and to reduce their contact with other people to only those necessary. In Polish national media, information about necessary hygiene behaviors, including hand hygiene behaviors, were announced, but no dedicated campaign for secondary school students was released.

The applied questionnaire included questions about general characteristics of respondents (inter alia information necessary to verify the inclusion criteria), as well as information about hand hygiene behaviors and other individual protecting behaviors (not included in the conducted study). To gather the data, Google Forms (Alphabet Co., Mountain View, CA, USA) was used, while students received the link to the questionnaire after they provided informed consent to participate, as well as informed consent of parents/legal guardians that were collected by the school principals. The link was distributed by the school principal, who provided it directly to students participating in remote learning. The data that were gathered were anonymous, while neither data allowing identification of respondents nor sensitive data were collected.

To verify the inclusion criteria, respondents were asked about their age (open-ended question) and the school which they attend (open-ended question).

The section with questions about hand hygiene behaviors was divided into two parts, to ask respondents each question twice-for the current period of the COVID-19 global pandemic and for the period before the COVID-19 issue. To enable easier recall, the period of the COVID-19 global pandemic was defined as a period when students are in the system of remote learning and the period before the COVID-19 issue was defined as a period when students were not in the system of remote learning, being typical for their behaviors when there was no COVID-19 issue (e.g., December 2019). Such recall period is indicated as reliable for the studies conducted for children and adolescents for various behaviors, including dietary behaviors [28], physical activity behaviors [29], sexual behaviors [30], or injuries [31], but no study was conducted for reliability of handwashing behaviors reporting. Similarly, for adults, even longer recall periods are indicated as reliable for various behaviors, such as dietary behaviors [32], physical activity behaviors [33], or breastfeeding behaviors [34].

The questions were associated with frequency of washing hands, reasons for not washing hands, circumstances of washing hands, and procedure of handwashing.

The frequency of washing hands was asked by a simple close-ended question with the frequencies specified as a number per day, with the categories, as follows: not washing at all, 1-2 times, 3-5 times, 6-10 times, 11-15 times, 16-20 times, 21-30 times, more than 30 times.

The reasons for not washing hands, while it would be needed, were asked by a multiple-choice closed-ended question with the possible options to choose, as follows: In my opinion there is no need to do it, I don't feel like doing it, I have no time to do it, I am forgetting about it, It is constricted (e.g., there is no soap, there is no bathroom nearby), Due to side effects (e.g., skin problems due to frequent contact with soap), Other (to be described), Not applicable (I always wash my hands).

The circumstances of washing hands were assessed based on commonly applied Handwashing Habits Questionnaire (HHQ) [35-37], as developed by Tüzün et al. [38], based on the previous questionnaire by Üner et al. [39]. The circumstances of washing hands were listed and for each of them, respondents were asked a simple close-ended question to define if they wash their hands with the categories, as follows: always, sometimes, never. The asked circumstances of washing hands were presented, as follows: before meals, after meals, before using the restroom, after using the restroom, after coming back home, after handshaking, before going to bed, after waking up in the morning, after using public transportation, after touching animals (with an additional answer that it is not applicable for them), after handling animal waste (with an additional answer that it is not applicable for them), after handling animal food (with an additional answer that it is not applicable for them), 
before preparing meals (with an additional answer that it is not applicable for them), after preparing meals (with an additional answer that it is not applicable for them), after money exchange, after blowing nose, after sneezing, after coughing, after touching garbage (with an additional answer that it is not applicable for them), before touching sick people, after touching sick people, after combing their hair (with an additional answer that it is not applicable for them), after cleaning their home (with an additional answer that it is not applicable for them), after washing dishes (with an additional answer that it is not applicable for them), after doing laundry (with an additional answer that it is not applicable for them), after contacting babies (with an additional answer that it is not applicable for them), after changing diapers (with an additional answer that it is not applicable for them), when hands are visibly soiled. The asked circumstances of washing hands were in agreement with the general recommendations by WHO [13,40], UNICEF [5], and CDC [6,41,42].

The procedure of handwashing was divided into steps that were listed and for each of them, respondents were asked a simple close-ended question to define if they include this step with the categories, as follows: always, sometimes, never. The asked steps of handwashing procedure were presented, as follows: folding sleeves (with an additional answer that this step is not applicable for them), removing watch and bracelets (with an additional answer that this step is not applicable for them), removing rings before or during handwashing (with an additional answer that this step is not applicable for them), using soap, using warm water, soaking hands before using soap (with an additional answer that this step is not applicable for them, as they do not use soap), careful making soap lather on whole hands (with an additional answer that this step is not applicable for them, as they do not use soap), turning the faucet off with hand (reverse question, as for the proper procedure the faucet should not be touched by already washed hand), drying hands with towel. The asked procedure of handwashing was based on the recommendations by WHO [13,40], UNICEF [5], and CDC [6,41,42].

\subsection{Statistical Analysis}

In order to compare the answers gathered for the current period of the COVID-19 global pandemic and for the period before the COVID-19 issue in the recruited national sample of Polish adolescents, the $\mathrm{chi}^{2}$ test was used. The distribution was verified while using Shapiro-Wilk test. The significance level of $p \leq 0.05$ was attributed to significant differences between answers. The statistical analysis was conducted while using Statgraphics Plus for Windows 4.0 (Statgraphics Technologies Inc., The Plains, VA, USA).

\section{Results}

The general characteristics of the studied population is presented in Table 1. The recruited participants were at the age of 15-20 years, while majority of them were 17 years old.

The declared frequency of washing hands and reasons for not washing hands in the studied population of Polish adolescents, for the period before the COVID-19 issue and during the COVID-19 global pandemic, are presented in Table 2, while the declared frequency of washing hands and reasons for not washing hands in the studied population of Polish adolescents, for the period before the COVID-19 issue and during the COVID-19 global pandemic distributed by region of Poland, are presented in Supplementary Tables S1 and S2. The declared daily frequency of washing hands during the COVID-19 global pandemic was significantly higher than before $(p<0.0001)$, as the majority of respondents declared 6-15 times a day (58.4\%) for the period during the COVID-19 global pandemic and 3-10 times a day (68.1\%) for the period before the COVID-19 issue. Moreover, it should be indicated that, as for the period before the COVID-19 issue, some respondents declared not washing hands at all or doing it very rarely (1-2 times a day) (11.9\%), while during the COVID-19 global pandemic everybody declared doing it, and the share of respondents doing it very rarely was minor $(1.9 \%)$. 
Table 1. The general characteristics of the studied population of Polish adolescents.

\begin{tabular}{|c|c|c|c|}
\hline \multicolumn{3}{|c|}{ Characteristic } & \multirow{3}{*}{$\begin{array}{c}\text { Number (\%) } \\
814(35.0 \%) \\
1509(65.0 \%)\end{array}$} \\
\hline & Gondor & Male & \\
\hline & Genaer & Female & \\
\hline \multirow{6}{*}{\multicolumn{2}{|c|}{ Region }} & Central & $104(4.5 \%)$ \\
\hline & & North-West & $265(11.4 \%)$ \\
\hline & & East & $422(18.2 \%)$ \\
\hline & & South & $610(26.3 \%)$ \\
\hline & & South-West & $588(25.3 \%)$ \\
\hline & & North & $334(14.4 \%)$ \\
\hline \multicolumn{3}{|c|}{ Age (years) } & Value \\
\hline \multirow{2}{*}{\multicolumn{2}{|c|}{ Total }} & Mean \pm SD & $16.9 \pm 1.3$ \\
\hline & & Median * (range) & $17.0(15-20)$ \\
\hline \multirow{4}{*}{ Gender } & \multirow{2}{*}{ Male } & Mean \pm SD & $16.9 \pm 1.3$ \\
\hline & & Median * (range) & $17(15-20)$ \\
\hline & \multirow{2}{*}{ Female } & Mean \pm SD & $16.9 \pm 1.3$ \\
\hline & & Median * (range) & $17(15-20)$ \\
\hline \multirow{12}{*}{ Region } & \multirow{2}{*}{ Central } & Mean \pm SD & $16.8 \pm 1.2$ \\
\hline & & Median * (range) & $17(15-20)$ \\
\hline & \multirow{2}{*}{ North-West } & Mean \pm SD & $17.3 \pm 1.4$ \\
\hline & & Median * (range) & $17(15-20)$ \\
\hline & \multirow{2}{*}{ East } & Mean \pm SD & $16.9 \pm 1.3$ \\
\hline & & Median * (range) & $17(15-20)$ \\
\hline & \multirow{2}{*}{ South } & Mean $\pm S D$ & $16.6 \pm 1.2$ \\
\hline & & Median * (range) & $16(15-20)$ \\
\hline & \multirow{2}{*}{ South-West } & Mean \pm SD & $17.1 \pm 1.4$ \\
\hline & & Median * (range) & $17(15-20)$ \\
\hline & \multirow{2}{*}{ North } & Mean \pm SD & $17.0 \pm 1.5$ \\
\hline & & Median * (range) & $17(15-20)$ \\
\hline
\end{tabular}

* nonparametric distribution (verified using Shapiro-Wilk test).

The share of respondents declaring washing their hands always while it would be needed was significantly higher for the period during the COVID-19 global pandemic (54.8\%), than it was for the period before the COVID-19 issue $(35.6 \% ; p<0.0001)$. At the same time, there was a lower share of respondents declaring various reasons for not washing hands, including their personal opinion that it is not needed $(p<0.0001)$, not feeling like doing it $(p<0.0001)$, having no time to do it $(p<0.0001)$, and the fact that it is constricted $(p<0.0001)$. Only in the case of the side effects, the frequency of declaring it as a reason for not washing hands did not differ for the compared periods $(p=0.6783)$.

The declared meal-associated and personal-hygiene-associated circumstances of washing hands, based on Handwashing Habits Questionnaire [38], in the studied population of Polish adolescents, for the period before the COVID-19 issue and during the COVID-19 global pandemic are presented in Table 3. For all the assessed circumstances associated with meals, including situations before meals $(p<0.0001)$, after meals $(p<0.0001)$, before preparing meals $(p<0.0001)$, and after preparing meals $(p<0.0001)$, the share of respondents declaring washing their hands always was significantly higher for the period during the COVID-19 global pandemic, than it was for the period before the COVID-19 issue. The highest share during the COVID-19 global pandemic was stated for situations before preparing meals $(84.5 \%)$ and before meals $(70.0 \%)$. 
Table 2. The declared frequency of washing hands and reasons for not washing hands in the studied population of Polish adolescents, for the period before the COVID-19 issue and during the COVID-19 global pandemic (comparison conducted while using chi ${ }^{2}$ test).

\begin{tabular}{|c|c|c|c|}
\hline Characteristic & $\begin{array}{l}\text { Before the } \\
\text { COVID-19 Issue }\end{array}$ & $\begin{array}{l}\text { During the Current Period of } \\
\text { COVID-19 Global Pandemic }\end{array}$ & $p$ \\
\hline \multicolumn{4}{|c|}{ Frequency of Washing Hands } \\
\hline Not washing at all & $9(0.4 \%)$ & $0(0.0 \%)$ & \multirow{8}{*}{$<0.0001$} \\
\hline $1-2$ times & $265(11.5 \%)$ & $45(1.9 \%)$ & \\
\hline $3-5$ times & $938(40.5 \%)$ & $370(15.9 \%)$ & \\
\hline $6-10$ times & $638(27.6 \%)$ & $832(35.8 \%)$ & \\
\hline $11-15$ times & $289(12.5 \%)$ & $525(22.6 \%)$ & \\
\hline 16-20 times & $109(4.7 \%)$ & $290(12.5 \%)$ & \\
\hline 21-30 times & $41(1.8 \%)$ & $163(7.0 \%)$ & \\
\hline More than 30 times & $34(1.5 \%)$ & $98(4.2 \%)$ & \\
\hline \multicolumn{4}{|c|}{ Reasons for not Washing Hands } \\
\hline In my opinion there is no need to do it & $337(11.6 \%)$ & $200(7.5 \%)$ & $<0.0001$ \\
\hline I don't feel like doing it & $298(10.2 \%)$ & $121(4.5 \%)$ & $<0.0001$ \\
\hline I have no time to do it & $166(5.7 \%)$ & $58(2.2 \%)$ & $<0.0001$ \\
\hline I am forgetting about it & $761(26.2 \%)$ & $585(21.8 \%)$ & $<0.0001$ \\
\hline $\begin{array}{l}\text { It is constricted (e.g., there is no soap, } \\
\text { there is no bathroom nearby) }\end{array}$ & $148(5.1 \%)$ & $65(2.4 \%)$ & $<0.0001$ \\
\hline $\begin{array}{l}\text { Due to side effects (e.g., skin problems } \\
\text { due to frequent contact with soap) }\end{array}$ & $148(5.1 \%)$ & $156(5.8 \%)$ & 0.6783 \\
\hline Other * & $15(0.5 \%)$ & $29(1.1 \%)$ & 0.0490 \\
\hline Not applicable (I always wash my hands) & $1037(35.6 \%)$ & $1469(54.8 \%)$ & $<0.0001$ \\
\hline I always wash my hands & $1037(35.6 \%)$ & $1469(54.8 \%)$ & \multirow{2}{*}{$<0.0001$} \\
\hline Various reasons for not washing $* *$ & $1286(64.4 \%)$ & $854(45.2 \%)$ & \\
\hline
\end{tabular}

For the majority of assessed circumstances associated with personal hygiene, including situations after using the restroom $(p<0.0001)$, before going to bed $(p<0.0001)$, after waking up in the morning $(p<0.0001)$, and after combing their hair $(p<0.0001)$, the share of respondents declaring washing their hands always was significantly higher for the period during the COVID-19 global pandemic, than it was for the period before the COVID-19 issue. The highest share during the COVID-19 global pandemic was stated for situations after using the restroom (95.7\%) and after waking up in the morning $(46.1 \%)$.

The declared leaving-home-associated and socializing-associated circumstances of washing hands, based on the Handwashing Habits Questionnaire [38], in the studied population of Polish adolescents, for the period before the COVID-19 issue and during the COVID-19 global pandemic are presented in Table 4 . For all the assessed circumstances associated with leaving home, including situations after coming back home $(p<0.0001)$, after using a public transportation $(p<0.0001)$, after money exchange $(p<0.0001)$, and when hands are visibly soiled $(p<0.0001)$, the share of respondents declaring washing their hands always was significantly higher for the period during the COVID-19 global pandemic, than it was for the period before the COVID-19 issue. The highest share during the COVID-19 global pandemic was stated for situations when hands are visibly soiled (96.6\%) and after coming back home $(90.1 \%)$. 
Table 3. The declared meal-associated and personal-hygiene-associated circumstances of washing hands, based on the Handwashing Habits Questionnaire [38], in the studied population of Polish adolescents, for the period before the COVID-19 issue and during the COVID-19 global pandemic (comparison conducted while using $\mathrm{chi}^{2}$ test).

\begin{tabular}{|c|c|c|c|}
\hline Characteristics & Before the COVID-19 Issue & $\begin{array}{l}\text { During the Current Period of } \\
\text { COVID-19 Global Pandemic }\end{array}$ & $p$ \\
\hline \multicolumn{4}{|c|}{ Before meals } \\
\hline Always & $1528(65.8 \%)$ & $1625(70.0 \%)$ & \multirow{3}{*}{$<0.0001$} \\
\hline Sometimes & $647(27.9 \%)$ & $631(27.2 \%)$ & \\
\hline Never & $148(6.4 \%)$ & $67(2.9 \%)$ & \\
\hline \multicolumn{4}{|c|}{ After meals } \\
\hline Always & $756(32.5 \%)$ & $674(29.0 \%)$ & \multirow{3}{*}{$<0.0001$} \\
\hline Sometimes & $1073(46.2 \%)$ & $1307(56.3 \%)$ & \\
\hline Never & $494(21.3 \%)$ & $342(14.7 \%)$ & \\
\hline \multicolumn{4}{|c|}{ Before preparing meals } \\
\hline Always & $1787(76.9 \%)$ & $1963(84.5 \%)$ & \multirow{4}{*}{$<0.0001$} \\
\hline Sometimes & $317(13.6 \%)$ & $188(8.1 \%)$ & \\
\hline Never & $58(2.5 \%)$ & $26(1.1 \%)$ & \\
\hline Not applicable & $161(6.9 \%)$ & $146(6.3 \%)$ & \\
\hline \multicolumn{4}{|c|}{ After preparing meals } \\
\hline Always & $1279(55.1 \%)$ & $1581(68.1 \%)$ & \multirow{4}{*}{$<0.0001$} \\
\hline Sometimes & $673(29.0 \%)$ & $521(22.4 \%)$ & \\
\hline Never & $203(8.7 \%)$ & $75(3.2 \%)$ & \\
\hline Not applicable & $168(7.2 \%)$ & $146(6.3 \%)$ & \\
\hline \multicolumn{4}{|c|}{ Before using the restroom } \\
\hline Always & $351(15.1 \%)$ & $334(14.4 \%)$ & \multirow{3}{*}{0.4545} \\
\hline Sometimes & $853(36.7 \%)$ & $893(38.4 \%)$ & \\
\hline Never & $1119(48.2 \%)$ & $1096(47.2 \%)$ & \\
\hline \multicolumn{4}{|c|}{ After using the restroom } \\
\hline Always & $2084(89.7 \%)$ & $2222(95.7 \%)$ & \multirow{3}{*}{$<0.0001$} \\
\hline Sometimes & $219(9.4 \%)$ & $91(3.9 \%)$ & \\
\hline Never & $20(0.9 \%)$ & $10(0.4 \%)$ & \\
\hline \multicolumn{4}{|c|}{ Before going to bed } \\
\hline Always & $860(37 \%)$ & $1057(45.5 \%)$ & \multirow{3}{*}{$<0.0001$} \\
\hline Sometimes & $699(30.1 \%)$ & $763(32.8 \%)$ & \\
\hline Never & $764(32.9 \%)$ & $503(21.7 \%)$ & \\
\hline \multicolumn{4}{|c|}{ After waking up in the morning } \\
\hline Always & $930(40.0 \%)$ & $1071(46.1 \%)$ & \multirow{3}{*}{$<0.0001$} \\
\hline Sometimes & 718 (30.9\%) & 757 (32.6\%) & \\
\hline Never & $675(29.1 \%)$ & $495(21.3 \%)$ & \\
\hline \multicolumn{4}{|c|}{ After combing their hair } \\
\hline Always & $453(19.5 \%)$ & $483(20.8 \%)$ & \multirow{4}{*}{$<0.0001$} \\
\hline Sometimes & $653(28.1 \%)$ & $794(34.2 \%)$ & \\
\hline Never & $1008(43.4 \%)$ & $860(37.0 \%)$ & \\
\hline Not applicable & $209(9.0 \%)$ & $186(8.0 \%)$ & \\
\hline
\end{tabular}


Table 4. The declared leaving-home-associated and socializing-associated circumstances of washing hands, based on the Handwashing Habits Questionnaire [38], in the studied population of Polish adolescents, for the period before the COVID-19 issue and during the COVID-19 global pandemic (comparison conducted while using $\mathrm{chi}^{2}$ test).

\begin{tabular}{|c|c|c|c|}
\hline Characteristics & Before the COVID-19 Issue & $\begin{array}{l}\text { During the Current Period of } \\
\text { COVID-19 Global Pandemic }\end{array}$ & $p$ \\
\hline \multicolumn{4}{|c|}{ After coming back home } \\
\hline Always & $1548(66.6 \%)$ & $2093(90.1 \%)$ & \multirow{3}{*}{$<0.0001$} \\
\hline Sometimes & $689(29.7 \%)$ & $214(9.2 \%)$ & \\
\hline Never & $86(3.7 \%)$ & $16(0.7 \%)$ & \\
\hline \multicolumn{4}{|c|}{ After using public transportation } \\
\hline Always & $1116(48.0 \%)$ & $1862(80.2 \%)$ & \multirow{3}{*}{$<0.0001$} \\
\hline Sometimes & $897(38.6 \%)$ & $337(14.5 \%)$ & \\
\hline Never & $310(13.3 \%)$ & $124(5.3 \%)$ & \\
\hline \multicolumn{4}{|c|}{ After money exchange } \\
\hline Always & $652(28.1 \%)$ & $1270(54.7 \%)$ & \multirow{3}{*}{$<0.0001$} \\
\hline Sometimes & $876(37.7 \%)$ & $678(29.2 \%)$ & \\
\hline Never & $795(34.2 \%)$ & $375(16.1 \%)$ & \\
\hline \multicolumn{4}{|c|}{ When hands are visibly soiled } \\
\hline Always & $2170(93.4 \%)$ & $2244(96.6 \%)$ & \multirow{3}{*}{$<0.0001$} \\
\hline Sometimes & $116(5.0 \%)$ & $60(2.6 \%)$ & \\
\hline Never & $37(1.6 \%)$ & $19(0.8 \%)$ & \\
\hline \multicolumn{4}{|c|}{ After handshaking } \\
\hline Always & $434(18.7 \%)$ & $1031(44.4 \%)$ & \multirow{3}{*}{$<0.0001$} \\
\hline Sometimes & $1023(44.0 \%)$ & $928(39.9 \%)$ & \\
\hline Never & $866(37.3 \%)$ & $364(15.7 \%)$ & \\
\hline \multicolumn{4}{|c|}{ After touching animals } \\
\hline Always & $1033(44.5 \%)$ & $1115(48.0 \%)$ & \multirow{4}{*}{0.0006} \\
\hline Sometimes & $673(29.0 \%)$ & $627(27.0 \%)$ & \\
\hline Never & $203(8.7 \%)$ & $143(6.2 \%)$ & \\
\hline Not applicable & $414(17.8 \%)$ & $438(18.9 \%)$ & \\
\hline \multicolumn{4}{|c|}{ After handling animal waste } \\
\hline Always & $1525(65.6 \%)$ & $1653(71.2 \%)$ & \multirow{4}{*}{$<0.0001$} \\
\hline Sometimes & $215(9.3 \%)$ & $125(5.4 \%)$ & \\
\hline Never & $73(3.1 \%)$ & $45(1.9 \%)$ & \\
\hline Not applicable & $510(22.0 \%)$ & $500(21.5 \%)$ & \\
\hline \multicolumn{4}{|c|}{ After handling animal food } \\
\hline Always & $1118(48.1 \%)$ & $1254(54.0 \%)$ & \multirow{4}{*}{$<0.0001$} \\
\hline Sometimes & $514(22.1 \%)$ & $464(20.0 \%)$ & \\
\hline Never & $207(8.9 \%)$ & $129(5.6 \%)$ & \\
\hline Not applicable & $484(20.8 \%)$ & $476(20.5 \%)$ & \\
\hline \multicolumn{4}{|c|}{ After contacting babies } \\
\hline Always & $325(14.0 \%)$ & $362(15.6 \%)$ & \multirow{4}{*}{0.0053} \\
\hline Sometimes & $477(20.5 \%)$ & $402(17.3 \%)$ & \\
\hline Never & $252(10.8 \%)$ & $175(7.5 \%)$ & \\
\hline Not applicable & $1269(54.6 \%)$ & $1384(59.6 \%)$ & \\
\hline \multicolumn{4}{|c|}{ After changing diapers } \\
\hline Always & $526(22.6 \%)$ & $528(22.7 \%)$ & \multirow{4}{*}{0.0001} \\
\hline Sometimes & $124(5.3 \%)$ & $67(2.9 \%)$ & \\
\hline Never & $68(2.9 \%)$ & $40(1.7 \%)$ & \\
\hline Not applicable & $1605(69.1 \%)$ & $1688(72.7 \%)$ & \\
\hline
\end{tabular}


For all the assessed circumstances associated with socializing, including situations after handshaking $(p<0.0001)$, after touching animals $(p=0.0006)$, after handling animal waste $(p<0.0001)$, after handling animal food $(p<0.0001)$, and after contacting babies $(p<0.0001)$, the share of respondents declaring washing their hands always was significantly higher for the period during the COVID-19 global pandemic, than it was for the period before the COVID-19 issue. The highest share during the COVID-19 global pandemic was stated for situation after handling animal waste (71.2\%) and after handling animal food (54.0\%). At the same time, for changing the diapers, the share of respondents declaring not doing it was higher for the period during the COVID-19 global pandemic, than it was for the period before the COVID-19 issue $(p<0.0001)$.

The declared health-associated and household-chores-associated circumstances of washing hands, based on the Handwashing Habits Questionnaire [38], in the studied population of Polish adolescents, for the period before the COVID-19 issue and during the COVID-19 global pandemic are presented in Table 5. For all the assessed circumstances associated with health, including situations after blowing nose $(p<0.0001)$, after sneezing $(p=0.0006)$, after coughing $(p<0.0001)$, before touching sick people $(p<0.0001)$, and after touching sick people $(p<0.0001)$, the share of respondents declaring washing their hands always was significantly higher for the period during the COVID-19 global pandemic, than it was for the period before the COVID-19 issue. The highest share during the COVID-19 global pandemic was stated for situations after touching sick people $(85.0 \%)$ and before touching sick people (45.3\%).

For all the assessed circumstances associated with household chores, including situations after touching garbage $(p<0.0001)$, after cleaning their home $(p=0.0006)$, after washing dishes $(p<0.0001)$, and after doing laundry $(p<0.0001)$, the share of respondents declaring washing their hands always was significantly higher for the period during the COVID-19 global pandemic, than it was for the period before the COVID-19 issue. The highest share during the COVID-19 global pandemic was stated for situations after touching garbage $(76.5 \%)$ and after cleaning their home $(69.9 \%)$.

The declared procedure of handwashing in the studied population of Polish adolescents, for the period before the COVID-19 issue and during the COVID-19 global pandemic is presented in Table 6 . For the majority of assessed steps of procedure, including folding sleeves $(p<0.0001)$, using soap $(p<0.0001)$, using warm water $(p<0.0001)$, soaking hands before using soap $(p<0.0001)$, careful making soap lather on whole hands $(p<0.0001)$, and drying hands with towel $(p<0.0001)$, the share of respondents declaring always including them was significantly higher for the period during the COVID-19 global pandemic, than it was for the period before the COVID-19 issue. The highest share during the COVID-19 global pandemic was stated for using soap (94.7\%) and drying hands with towel $(81.4 \%)$. For the reverse question, associated with turning the faucet off with a hand, the share of respondents declaring not including it was significantly higher for the period during the COVID-19 global pandemic, than it was for the period before the COVID-19 issue $(p<0.0001)$. At the same time, for removing watch and bracelet $(p=0.0006)$, as well as removing rings before or during handwashing $(p=0.0129)$, the share of respondents declaring not wearing them was higher for the period during the COVID-19 global pandemic, than it was for the period before the COVID-19 issue. 
Table 5. The declared health-associated and household-chores-associated circumstances of washing hands, based on the Handwashing Habits Questionnaire [38], in the studied population of Polish adolescents, for the period before the COVID-19 issue and during the COVID-19 global pandemic (comparison conducted while using $\mathrm{chi}^{2}$ test).

\begin{tabular}{|c|c|c|c|}
\hline Characteristics & Before the COVID-19 Issue & $\begin{array}{l}\text { During the Current Period of } \\
\text { COVID-19 Global Pandemic }\end{array}$ & $p$ \\
\hline \multicolumn{4}{|c|}{ After blowing nose } \\
\hline Always & $633(27.2 \%)$ & $908(39.1 \%)$ & \multirow{3}{*}{$<0.0001$} \\
\hline Sometimes & $1028(44.3 \%)$ & $1003(43.2 \%)$ & \\
\hline Never & $662(28.5 \%)$ & $412(17.7 \%)$ & \\
\hline \multicolumn{4}{|c|}{ After sneezing } \\
\hline Always & $681(29.3 \%)$ & $1030(44.3 \%)$ & \multirow{3}{*}{$<0.0001$} \\
\hline Sometimes & $1048(45.1 \%)$ & $945(40.7 \%)$ & \\
\hline Never & $594(25.6 \%)$ & $348(15 \%)$ & \\
\hline \multicolumn{4}{|c|}{ After coughing } \\
\hline Always & $621(26.7 \%)$ & $941(40.5 \%)$ & \multirow{3}{*}{$<0.0001$} \\
\hline Sometimes & $1009(43.4 \%)$ & $979(42.1 \%)$ & \\
\hline Never & $693(29.8 \%)$ & $403(17.3 \%)$ & \\
\hline \multicolumn{4}{|c|}{ Before touching sick people } \\
\hline Always & $734(31.6 \%)$ & $1053(45.3 \%)$ & \multirow{3}{*}{$<0.0001$} \\
\hline Sometimes & $793(34.1 \%)$ & $692(29.8 \%)$ & \\
\hline Never & $796(34.3 \%)$ & $578(24.9 \%)$ & \\
\hline \multicolumn{4}{|c|}{ After touching sick people } \\
\hline Always & $1475(63.5 \%)$ & $1974(85.0 \%)$ & \multirow{3}{*}{$<0.0001$} \\
\hline Sometimes & $631(27.2 \%)$ & $257(11.1 \%)$ & \\
\hline Never & $217(9.3 \%)$ & $92(4.0 \%)$ & \\
\hline \multicolumn{4}{|c|}{ After touching garbage } \\
\hline Always & $1571(67.6 \%)$ & $1777(76.5 \%)$ & \multirow{4}{*}{$<0.0001$} \\
\hline Sometimes & $452(19.5 \%)$ & $275(11.8 \%)$ & \\
\hline Never & $93(4.0 \%)$ & $40(1.7 \%)$ & \\
\hline Not applicable & $207(8.9 \%)$ & $231(9.9 \%)$ & \\
\hline \multicolumn{4}{|c|}{ After cleaning their home } \\
\hline Always & $1361(58.6 \%)$ & $1623(69.9 \%)$ & \multirow{4}{*}{$<0.0001$} \\
\hline Sometimes & $693(29.8 \%)$ & $556(23.9 \%)$ & \\
\hline Never & $195(8.4 \%)$ & $84(3.6 \%)$ & \\
\hline Not applicable & $74(3.2 \%)$ & $60(2.6 \%)$ & \\
\hline \multicolumn{4}{|c|}{ After washing dishes } \\
\hline Always & $1275(54.9 \%)$ & $1494(64.3 \%)$ & \multirow{4}{*}{$<0.0001$} \\
\hline Sometimes & $459(19.8 \%)$ & $344(14.8 \%)$ & \\
\hline Never & $313(13.5 \%)$ & $217(9.3 \%)$ & \\
\hline Not applicable & $276(11.9 \%)$ & $268(11.5 \%)$ & \\
\hline \multicolumn{4}{|c|}{ After doing laundry } \\
\hline Always & $578(24.9 \%)$ & $653(28.1 \%)$ & \multirow{4}{*}{$<0.0001$} \\
\hline Sometimes & $572(24.6 \%)$ & $635(27.3 \%)$ & \\
\hline Never & $553(23.8 \%)$ & $432(18.6 \%)$ & \\
\hline Not applicable & $620(26.7 \%)$ & $603(26.0 \%)$ & \\
\hline
\end{tabular}


Table 6. The declared procedure of handwashing in the studied population of Polish adolescents, for the period before the COVID-19 issue and during the COVID-19 global pandemic (comparison conducted while using $\mathrm{chi}^{2}$ test).

\begin{tabular}{|c|c|c|c|}
\hline Characteristics & Before the COVID-19 Issue & $\begin{array}{l}\text { During the Current Period of } \\
\text { COVID-19 Global Pandemic }\end{array}$ & $p$ \\
\hline \multicolumn{4}{|c|}{ Folding sleeves } \\
\hline Always & $1165(50.2 \%)$ & $1243(53.5 \%)$ & \multirow{4}{*}{$<0.0001$} \\
\hline Sometimes & $597(25.7 \%)$ & $480(20.7 \%)$ & \\
\hline Never & $154(6.6 \%)$ & $76(3.3 \%)$ & \\
\hline Not applicable & $407(17.5 \%)$ & $524(22.6 \%)$ & \\
\hline \multicolumn{4}{|c|}{ Removing watch and bracelets } \\
\hline Always & $321(13.8 \%)$ & $317(13.6 \%)$ & \multirow{4}{*}{0.0006} \\
\hline Sometimes & $450(19.4 \%)$ & $455(19.6 \%)$ & \\
\hline Never & $295(12.7 \%)$ & $209(9.0 \%)$ & \\
\hline Not applicable & $1257(54.1 \%)$ & $1342(57.8 \%)$ & \\
\hline \multicolumn{4}{|c|}{ Removing rings before or during handwashing } \\
\hline Always & $282(12.1 \%)$ & $261(11.2 \%)$ & \multirow{4}{*}{0.0129} \\
\hline Sometimes & $202(8.7 \%)$ & $166(7.1 \%)$ & \\
\hline Never & $260(11.2 \%)$ & $219(9.4 \%)$ & \\
\hline Not applicable & $1579(68.0 \%)$ & $1677(72.2 \%)$ & \\
\hline \multicolumn{4}{|c|}{ Using soap } \\
\hline Always & $1977(85.1 \%)$ & $2199(94.7 \%)$ & \multirow{3}{*}{$<0.0001$} \\
\hline Sometimes & $329(14.2 \%)$ & $118(5.1 \%)$ & \\
\hline Never & $17(0.7 \%)$ & $6(0.3 \%)$ & \\
\hline \multicolumn{4}{|c|}{ Using warm water } \\
\hline Always & $1352(58.2 \%)$ & $1503(64.7 \%)$ & \multirow{3}{*}{$<0.0001$} \\
\hline Sometimes & $910(39.2 \%)$ & $777(33.4 \%)$ & \\
\hline Never & $61(2.6 \%)$ & $43(1.9 \%)$ & \\
\hline \multicolumn{4}{|c|}{ Soaking hands before using soap } \\
\hline Always & $1577(67.9 \%)$ & $1704(73.4 \%)$ & \multirow{4}{*}{$<0.0001$} \\
\hline Sometimes & $542(23.3 \%)$ & $415(17.9 \%)$ & \\
\hline Never & $198(8.5 \%)$ & $201(8.7 \%)$ & \\
\hline $\begin{array}{l}\text { Not applicable - do } \\
\text { not use soap }\end{array}$ & $6(0.3 \%)$ & $3(0.1 \%)$ & \\
\hline \multicolumn{4}{|c|}{ Careful making soap lather on whole hands } \\
\hline Always & $1098(47.3 \%)$ & $1427(61.4 \%)$ & \multirow{4}{*}{$<0.0001$} \\
\hline Sometimes & $1000(43.0 \%)$ & $796(34.3 \%)$ & \\
\hline Never & $216(9.3 \%)$ & $99(4.3 \%)$ & \\
\hline $\begin{array}{l}\text { Not applicable - do } \\
\text { not use soap }\end{array}$ & $9(0.4 \%)$ & $1(0.0 \%)$ & \\
\hline \multicolumn{4}{|c|}{ Turning the faucet off with hand * } \\
\hline Always & $1438(61.9 \%)$ & $1190(51.2 \%)$ & \multirow{3}{*}{$<0.0001$} \\
\hline Sometimes & $586(25.2 \%)$ & $628(27 \%)$ & \\
\hline Never & $299(12.9 \%)$ & $505(21.7 \%)$ & \\
\hline \multicolumn{4}{|c|}{ Drying hands with towel } \\
\hline Always & $1745(75.1 \%)$ & $1890(81.4 \%)$ & \multirow{3}{*}{$<0.0001$} \\
\hline Sometimes & $501(21.6 \%)$ & $376(16.2 \%)$ & \\
\hline Never & $44(3.3 \%)$ & $57(2.5 \%)$ & \\
\hline
\end{tabular}

\footnotetext{
${ }^{*}$ reverse question, as for the proper procedure the facet should not be touched by already washed hand.
} 


\section{Discussion}

In the assessed cohort of Polish adolescents, during the COVID-19 pandemic all the analyzed hand hygiene behaviors were improved, compared with those before the COVID-19 issue. However, the hand hygiene behaviors in Polish adolescents were still not satisfactory, as some adolescents declared not washing hands while it would be needed, or they declared improper procedure of handwashing.

The role of proper hand hygiene behaviors for COVID-19 prevention is reflected in a global interest in this issue, and it is indicated as a real-time indicator for transmission-reduction policies and population health literacy [43]. However, it is still indicated that hand hygiene should be monitored [44] and supported [45], while feedback is necessary [46], due to the fact that there are still inadequacies. Taking this into account, the results observed for the studied population of Polish adolescents must be interpreted as very positive, but still not satisfactory. In spite of the fact that during the COVID-19 pandemic all the assessed hand hygiene behaviors of Polish adolescents were improved, compared with those before, a number of adolescents still declared improper hand hygiene behaviors.

It should be emphasized that, during the COVID-19 global pandemic, while being in the system of remote learning and being recommended to stay at home and to reduce their contact with other people to only those necessary, some adolescents did not have a proper handwashing behaviors. Especially for basic hygiene behaviors, which are, in Poland, commonly taught even in primary school education, such as washing hands before meals, or after coming back home, it must be indicated that over $27 \%$ and over $9 \%$ of respondents, respectively, declared doing it only sometimes. Similarly, almost $40 \%$ of respondents declared washing hands only sometimes after handshaking. Last but not least, only $39 \%, 44 \%$, and $40 \%$ of respondents declared washing hands always after blowing their nose, sneezing, and coughing, respectively.

Comparing with the results observed by other authors, it must be indicated that it is not only in the Polish population that handwashing behaviors during the COVID-19 pandemic are not satisfactory. A similar situation was observed in the previously mentioned study by Chen et al. [16], conducted in Wuhan, where almost $60 \%$ of school students had improper handwashing behaviors. Likewise, during the Severe Acute Respiratory Syndrome (SARS) outbreak in 2002-2003 some hand hygiene behaviors also were not respected, even by hospital workers [47].

The issue of hand hygiene behaviors is especially important, while taking into account its general role, not only for COVID-19, but also for other infectious diseases in the community setting [48]. Moreover, in the current situation of the COVID-19 threat, constant hand hygiene accompanied by mask-wearing is the approach proven to slow the exponential spread of the virus [49]. In the review study by Di Gennaro et al. [50], it was indicated among the most recommended ways of COVID-19 prevention, along with using face mask, covering while coughing and sneezing, avoiding contact with infected people, maintaining an appropriate distance from people, refraining from touching eyes, nose, and mouth; while in case of symptoms, seeking medical care early and following advice given by healthcare provider. Taking this into account, the results that were gathered in the presented study indicate the important areas that should be covered in future hand hygiene education, not only in the population of Polish adolescents, but also other population groups.

It may be emphasized that the observations for SARS, based on the review by Fung and Cairncross [51], indicate that the decline of handwashing after the SARS issue in 2002-2003 was relatively minor, so the recommended behaviors that will be adapted by adolescents during the COVID-19 pandemic may promote a lifelong hand hygiene habits in this generation.

In spite of the fact that the study provided useful data about handwashing frequency and adherence to handwashing guidelines by the target population, which may be useful for designing public health communication interventions, some limitations of the study should be presented. The study was based on the handwashing behaviors recall for the current period of the COVID-19 global pandemic and for the period before the COVID-19 issue, which may be associated with recall bias and self-reporting bias. In general, respondents tend to struggle when using recall instruments: they tend to elide (i.e., merge together) experiences, have a poor sense of duration, and often lack motivation to complete 
the task [52]. At the same time, there are many reasons individuals might offer biased estimates of self-assessed behavior, ranging from a misunderstanding of what a proper measurement is to social-desirability bias, where the respondent wants to 'look good' in the survey, even if the survey is anonymous, that may be supposed for handwashing behaviors [53]. Moreover, as data were gathered via internet during the period of their remote learning due to COVID-19 global pandemic, the students who have no access to internet were not able to participate in the study. Last, but not least, there was a relatively low response rate of schools, which may have also influenced the results, although a relatively high response rate of students within schools was stated.

Based on the obtained results, some policy recommendations may be formulated. The recommended actions should include the necessity of constant hand hygiene education, conducted in schools, especially in terms of the COVID-19 global pandemic. However, not only schools should be engaged, but also other information channels, such as mass media, which may be, for adolescents, more effective than regular school education.

\section{Conclusions}

It may be concluded that during the COVID-19 pandemic, all the assessed hand hygiene behaviors of Polish adolescents were improved, compared with those before, but hand hygiene education is still necessary. It should include the basic recommendations, such as washing hands before meals, or after coming back home, as well as after blowing nose, sneezing, and coughing, as those hand hygiene behaviors are still not satisfactory. Moreover, it should include the recommendation of not handshaking, as a number of adolescents still do it and do not wash hands after. However, taking into account the improvement that is observable compared with the previous period, the COVID-19 pandemic may be an opportunity to form lifelong hand hygiene habits in this generation.

Supplementary Materials: The following are available online at http://www.mdpi.com/2071-1050/12/12/4930/s1. Supplementary Table S1. The declared frequency of washing hands in the studied population of Polish adolescents, for the period before the COVID-19 issue and during the COVID-19 global pandemic, distributed by region of Poland (comparison conducted while using chi $^{2}$ test). Supplementary Table S2. The declared reason of not washing hands in the studied population of Polish adolescents, for the period before the COVID-19 issue and during the COVID-19 global pandemic, distributed by region of Poland (comparison conducted while using chi $^{2}$ test).

Author Contributions: D.G. (Dominika Głąsska), D.S., and D.G. (Dominika Guzek) made the study conception and design; D.G. (Dominika Głąbska), D.S., and D.G. (Dominika Guzek) performed the research; D.G. (Dominika Głabska), D.S., and D.G. (Dominika Guzek) analyzed the data; D.G. (Dominika Głąbska), D.S., and D.G. (Dominika Guzek) interpreted the data; D.G. (Dominika Głąbska), D.S., and D.G. (Dominika Guzek) wrote the paper. All authors have read and agreed to the published version of the manuscript.

Funding: This research was funded by the Polish Ministry of Science and Higher Education within funds of Institute of Human Nutrition Sciences, Warsaw University of Life Sciences (WULS), for scientific research.

Conflicts of Interest: The authors declare no conflict of interest.

\section{References}

1. World Health Organization. WHO Announces COVID-19 Outbreak a Pandemic. Available online: http://www.euro.who.int/en/health-topics/health-emergencies/coronavirus-covid-19/news/news/2020/3/ who-announces-covid-19-outbreak-a-pandemic (accessed on 14 May 2020).

2. Gujski, M.; Raciborski, F.; Jankowski, M.; Nowicka, P.M.; Rakocy, K.; Pinkas, J. Epidemiological Analysis of the First 1389 Cases of COVID-19 in Poland: A Preliminary Report. Med. Sci. Monit. 2020, 26, e924702-1. [CrossRef] [PubMed]

3. Corey, B.L.; Mascola, J.R.; Fauci, A.S.; Collins, F.S. A strategic approach to COVID-19 vaccine R\&D. Science 2020, 368, 948-950. [CrossRef] [PubMed]

4. Cirrincione, L.; Plescia, F.; Ledda, C.; Rapisarda, V.; Martorana, D.; Moldovan, R.E.; Theodoridou, K.; Cannizzaro, E. COVID-19 Pandemic: Prevention and Protection Measures to Be Adopted at the Workplace. Sustainability 2020, 12, 3603. [CrossRef] 
5. United Nations International Children's Emergency Fund. Everything You Need to Know about Washing Your Hands to Protect against Coronavirus (COVID-19). Available online: https://www.unicef.org/coronavirus/ everything-you-need-know-about-washing-your-hands-protect-against-coronavirus-covid-19 (accessed on 14 May 2020).

6. Centers for Disease Control and Prevention. When and How to Wash Your Hands. Available online: https://www.cdc.gov/handwashing/when-how-handwashing.html (accessed on 14 May 2020).

7. Polish Chief Sanitary Inspectorate. Available online: https://gis.gov.pl/aktualnosci/komunikat-glownegoinspektora-sanitarnego-W-sprawie-potwierdzonego-przypadku-koronawirusa/ (accessed on 14 May 2020).

8. Polish National Institute of Public Health. Available online: https://www.pzh.gov.pl/sposoby-ograniczaniaryzyka-zakazenia-koronawirusem-plakat-do-pobrania/ (accessed on 14 May 2020).

9. Beiu, C.; Mihai, M.; Popa, L.; Cima, L.; Popescu, M.N. Frequent hand washing for COVID-19 prevention can cause hand dermatitis: Management tips. Cureus 2020, 12, e7506. [CrossRef] [PubMed]

10. Abtahi-Naeini, B. Frequent handwashing amidst the COVID-19 outbreak: Prevention of hand irritant contact dermatitis and other considerations. Health Sci. Rep. 2020, 3, e163. [CrossRef] [PubMed]

11. Yang, C. Does hand hygiene reduce SARS-CoV-2 transmission? Graefe's Arch. Clin. Exp. Ophthalmol. 2020, 258, 1133-1134. [CrossRef]

12. Bloomfield, S.F.; Aiello, A.E.; Cookson, B.; O’Boyle, C.; Larson, E.L. The effectiveness of hand hygiene procedures in reducing the risks of infections in home and community settings including handwashing and alcohol-based hand sanitizers. Am. J. Infect. Control 2007, 35, 27-64. [CrossRef]

13. WHO Guidelines on Hand Hygiene in Health Care: First Global Patient Safety Challenge Clean Care Is Safer Care; World Health Organization: Geneva, Switzerland, 2009; II, CONSENSUS RECOMMENDATIONS. Available online: https://www.ncbi.nlm.nih.gov/books/NBK144035/ (accessed on 14 May 2020).

14. Wang, C.; Pan, R.; Wan, X.; Tan, Y.; Xu, L.; Ho, C.S.; Ho, R.C. Immediate Psychological Responses and Associated Factors during the Initial Stage of the 2019 Coronavirus Disease (COVID-19) Epidemic among the General Population in China. Int. J. Environ. Res. Public Health 2020, 17, 1729. [CrossRef]

15. Cannizzaro, E.; Ramaci, T.; Cirrincione, L.; Plescia, F. Work-Related Stress, Physio-Pathological Mechanisms, and the Influence of Environmental Genetic Factors. Int. J. Environ. Res. Public Health 2019, 16, 4031. [CrossRef]

16. Chen, X.; Ran, L.; Liu, Q.; Hu, Q.; Du, Q.; Tan, X. Hand hygiene, mask-wearing behaviors and its associated factors during COVID-19 epidemic: A cross-sectional study among primary school students in Wuhan, China. Int. J. Environ. Res. Public Health 2020, 17, 2893. [CrossRef]

17. Peltzer, K.; Pengpid, S. Oral and hand hygiene behaviour and risk factors among in-school adolescents in four Southeast Asian countries. Int. J. Environ. Res. Public Health 2014, 11, 2780-2792. [CrossRef]

18. Kim, E.J.; Pai, A.J.; Kang, N.E.; Kim, W.K.; Kim, Y.S.; Moon, H.K.; Ha, A.W. The effects of food safety education on adolescents' hand hygiene behaviour: An analysis of stages of change. Nutr. Res. Pract. 2012, 6, 169-174. [CrossRef]

19. Ubheeram, J.; Biranija-Hurdoya, S.D. Effectiveness of hand hygiene education among a random sample of women from the community. J. Prev. Med. Hyg. 2017, 58, 53-55.

20. Wong, J.S.W.; Lee, J.K.F. The common missed handwashing instances and areas after 15 years of hand-hygiene education. J. Environ. Public Health 2019, 2019, 5928924. [CrossRef]

21. Curtis, V.A.; Danquah, L.O.; Aunger, R.V. Planned, motivated and habitual hygiene behaviour: An eleven country review. Health Educ. Res. 2009, 24, 655-673. [CrossRef]

22. Dixit, D.; Hagtvedt, R.; Reay, T.; Ballermann, M.; Forgie, S. Attitudes and beliefs about hand hygiene among paediatric residents: A qualitative study. BMJ Open 2012, 2, e002188. [CrossRef]

23. Gardner, B.; Lally, P.; Wardle, J. Making health habitual: The psychology of 'habit-formation' and general practice. Br. J. Gen. Pract. 2012, 62, 664-666. [CrossRef]

24. The Central Statistical Office in Poland December 2019. Available online: https://bdl.stat.gov.pl/BDL/dane/ podgrup/temat (accessed on 14 May 2020).

25. The Central Statistical Office in Poland December 2019. Available online: http://demografia.stat.gov.pl/ bazademografia/Tables.aspx (accessed on 14 May 2020).

26. Polish Ministry of National Education. Available online: https://rspo.men.gov.pl/ (accessed on 14 May 2020).

27. Polish Ministry of National Education. Available online: https://www.gov.pl/web/edukacja/zawieszeniezajec-w-szkolach (accessed on 14 May 2020). 
28. Vioque, J.; Garcia-de-la-Hera, M.; Gonzalez-Palacios, S.; Torres-Collado, L.; Notario-Barandiaran, L.; Oncina-Canovas, A.; Soler-Blasco, R.; Lozano, M.; Beneito, A.; Navarrete-Muñoz, E.M. Reproducibility and Validity of a Short Food Frequency Questionnaire for Dietary Assessment in Children Aged 7-9 Years in Spain. Nutrients 2019, 11, 933. [CrossRef]

29. Hidding, L.M.; Chinapaw, M.J.M.; van Poppel, M.N.M.; Mokkink, L.B.; Altenburg, T.M. An Updated Systematic Review of Childhood Physical Activity Questionnaires. Sports Med. 2018, 48, 2797-2842. [CrossRef]

30. McFarlane, M.; St Lawrence, J.S. Adolescents' recall of sexual behavior: Consistency of self-report and effect of variations in recall duration. J. Adolesc. Health 1999, 25, 199-206. [CrossRef]

31. Zhang, A.H.; Tao, F.B.; Yan, S.Q.; Xu, Y.Q. Influence of Retrospective Time Period on Reliability of Epidemiological Survey to Injuries. Zhonghua Liu Xing Bing Xue Za Zhi 2009, 30, 1010-1012.

32. Chavarro, J.E.; Rosner, B.A.; Sampson, L.; Willey, C.; Tocco, P.; Willett, W.C.; Chumlea, W.C.; Michels, K.B. Validity of adolescent diet recall 48 years later. Am. J. Epidemiol. 2009, 170, 1563-1570. [CrossRef] [PubMed]

33. Slattery, M.L.; Jacobs, D.R., Jr. Assessment of ability to recall physical activity of several years ago. Ann. Epidemiol. 1995, 5, 292-296. [CrossRef]

34. Natland, S.T.; Andersen, L.F.; Nilsen, T.I.; Forsmo, S.; Jacobsen, G.W. Maternal recall of breastfeeding duration twenty years after delivery. BMC Med. Res. Methodol. 2012, 12, 179. [CrossRef] [PubMed]

35. Sultana, M.; Mahumud, R.A.; Sarker, A.R.; Hossain, S.M. Hand hygiene knowledge and practice among university students: Evidence from Private Universities of Bangladesh. Risk Manag. Healthc. Policy 2016, 9 , 13-20. [CrossRef] [PubMed]

36. Ergin, A.; Bostanci, M.; Onal, O.; Bozkurt, A.I.; Ergin, N. Evaluation of students' social hand washing knowledge, practices, and skills in a university setting. Cent. Eur. J. Public Health 2011, 19, 222-226. [CrossRef] [PubMed]

37. Mbroh, L.A. Assessing Knowledge, Attitude and Practices of Hand Hygiene among University Students. Master's Thesis, Minnesota State University, Mankato, MN, USA, 24 June 2019.

38. Tüzün, H.; Karakaya, K.; Deniz, E.B. Turkey Handwashing Survey: Suggestion for taking the ecological model into better consideration. Environ. Health Prev. Med. 2015, 20, 325-331. [CrossRef]

39. Üner, S.; Sevencan, F.; Başaran, E.; Balc1, C.; Bilaloğlu, B. To determine some knowledge and attitudes related to the social hand washing of individuals who apply to a primary health center. TAF Prev. Med. Bull. 2009, 8, 207-216.

40. World Health Organization (WHO). Hand Hygiene: Why, How \& When? Available online: https: //www.who.int/gpsc/5may/Hand_Hygiene_Why_How_and_When_Brochure.pdf (accessed on 14 May 2020).

41. Centers for Disease Control and Prevention (CDC). Proper Hygiene When around Animals. Available online: https://www.cdc.gov/healthywater/hygiene/etiquette/around_animals.html (accessed on 14 May 2020).

42. Centers for Disease Control and Prevention (CDC). Handwashing: A Healthy Habit in the Kitchen. Available online: https://www.cdc.gov/handwashing/handwashing-kitchen.html (accessed on 14 May 2020).

43. Lin, Y.H.; Liu, C.H.; Chiu, Y.C. Google searches for the keywords of "wash hands" predict the speed of national spread of COVID-19 outbreak among 21 countries. Brain Behav. Immun. 2020. [CrossRef]

44. Cawthorne, K.R.; Cooke, R.P.D. Innovative technologies for hand hygiene monitoring are urgently needed in the fight against COVID-19. J. Hosp. Infect. 2020. [CrossRef]

45. Thampi, N.; Longtin, Y.; Peters, A.; Pittet, D.; Overy, K. It's in our hands: A rapid, international initiative to translate a hand hygiene song during the COVID-19 pandemic. J. Hosp. Infect. 2020. [CrossRef] [PubMed]

46. Gon, G.; Dancer, S.; Dreibelbis, R.; Graham, W.J.; Kilpatrick, C. Reducing hand recontamination of healthcare workers during COVID-19. Infect. Control Hosp. Epidemiol. 2020, 6, 1-2. [CrossRef] [PubMed]

47. Lau, J.T.; Fung, K.S.; Wong, T.W.; Kim, J.H.; Wong, E.; Chung, S.; Ho, D.; Chan, L.Y.; Lui, S.F.; Cheng, A. SARS transmission among hospital workers in Hong Kong. Emerg. Infect. Dis. 2004, 10, 280-286. [CrossRef] [PubMed]

48. Aiello, A.E.; Coulborn, R.M.; Perez, V.; Larson, E.L. Effect of hand hygiene on infectious disease risk in the community setting: A meta-analysis. Am. J. Public Health 2008, 98, 1372-1381. [CrossRef] [PubMed]

49. Ma, Q.X.; Shan, H.; Zhang, H.L.; Li, G.M.; Yang, R.M.; Chen, J.M. Potential utilities of mask-wearing and instant hand hygiene for fighting SARS-CoV-2. J. Med. Virol. 2020. [CrossRef]

50. Di Gennaro, F.; Pizzol, D.; Marotta, C.; Antunes, M.; Racalbuto, V.; Veronese, N.; Smith, L. Coronavirus Diseases (COVID-19) Current Status and Future Perspectives: A Narrative Review. Int. J. Environ. Res. Public Health 2020, 17, 2690. [CrossRef] 
51. Fung, I.C.; Cairncross, S. How often do you wash your hands? A review of studies of hand-washing practices in the community during and after the SARS outbreak in 2003. Int. J. Environ. Health Res. 2007, 17, 161-183. [CrossRef]

52. Ridley, K.; Olds, T.S.; Hill, A. The Multimedia Activity Recall for Children and Adolescents (MARCA): Development and evaluation. Int. J. Behav. Nutr. Phys. Act. 2006, 26, 10. [CrossRef]

53. Rosenman, R.; Tennekoon, V.; Hill, L.G. Measuring bias in self-reported data. Int. J. Behav. Healthc. Res. 2011, 2, 320-332. [CrossRef]

(C) 2020 by the authors. Licensee MDPI, Basel, Switzerland. This article is an open access article distributed under the terms and conditions of the Creative Commons Attribution (CC BY) license (http://creativecommons.org/licenses/by/4.0/). 